\title{
Oleanolic acid regulates NF-kB signaling by suppressing MafK expression in RAW 264.7 cells
}

\author{
Yu-Jin Hwang ${ }^{1}$, Jaewhan Song ${ }^{2}$, Haeng-Ran Kim ${ }^{1}$ E Kyung-A Hwang ${ }^{1, *}$ \\ ${ }^{1}$ Department of Agrofood Resources, National Academy of Agricultural Science, RDA, Wanju 565-850, ${ }^{2}$ Department of Biochemistry, College \\ of Life Science and Biotechnology, Yonsei University, Seoul 120-749, Korea
}

Oxidative stress and inflammation are common to many pathological conditions. Defense mechanisms protect cells from oxidative stress, but can become over-activated following injury and inflammation. NF-KB and Nrf2 transcription factors regulate proinflammatory and antioxidant gene expression, respectively. Studies have shown that many natural dietary compounds regulate NF- $\mathrm{KB}$ and Nrf2, preventing inflammation and oxidative stress. Here, we report major compounds of Prunella vulgaris var. lilacina such as rosmarinic acid, oleanolic acid, ursolic acid and caffeic acid as a potential therapeutic for oxidative stress and inflammation. The major compounds exhibited high anti-inflammatory activity, inhibiting NO, PGE2 production, NF- $\mathrm{kB}$ expression and activating Nrf2 expression. In addition, we examined the effect of major compounds on MafK expression. Among the compounds, oleanolic acid significantly decreased MafK expression and MafK-mediated p65 acetylation. These findings suggest that oleanolic acid as NF-KB inhibitors can potentially be used in therapeutic applications for the treatment of oxidative stressnduced diseases. [BMB Reports 2014; 47(9): 524-529]

\section{INTRODUCTION}

Inflammation, a physiological response to infection or tissue injury, plays a crucial role in many chronic diseases and various human cancers $(1,2)$. Nuclear factor-KB (NF-KB) is a transcription factor with multiple genetic targets that controls various cellular functions, including immune inflammatory responses, cell adhesion, differentiation, apoptosis, stress-induced responses, survival, and progression of most chronic diseases (3, 4). Because NF-KB activation has been shown to elicit chemo-resistance in certain tumors, it is a promising novel target for tumor therapy (5-7).

*Corresponding author. Tel: +82-63-238-3704; Fax: +82-63-2383844; E-mail: kah366@korea.kr

http://dx.doi.org/10.5483/BMBRep.2014.47.9.149

Received 17 July 2014, Revised 22 July 2014, Accepted 23 July 2014

Keywords: MafK, NF-kB, Nrf2, Oleanolic acid, p65 acetylation
Nrf2 is a member of the CNC-basic leucine zipper (CNC-bZIP) family of transcription factors and coordinately regulates the constitutive and inducible expression of antioxidant and phase II detoxification enzymes such as heme oxygenase-1 (HO-1) and NAD (P)H:quinone oxidoreductase 1 (NQO1) via cis-acting ARE DNA elements $(8,9)$. These cytoprotective genes can rapidly neutralize, detoxify, and remove invading xenobiotics. Accumulating evidence shows that $\mathrm{Nrf} 2$ is also a promising target for cancer chemoprevention $(10,11)$.

Recent evidence has suggested crosstalk between NF-KB and Nrf2 under oxidative stress. These two pathways are proposed to inhibit each other at their transcription level via protein-protein interactions or through secondary messenger effects. Thus, identification of factors that regulate crosstalk between NF- $\mathrm{KB}$ and $\mathrm{Nrf2}$ has garnered recent interest (12-14). As part of those studies, we recently identified a novel function of MafK, which can act as a modulator of NF- $\mathrm{KB}$ by inducing CBP-mediated p65 acetylation in vitro and in vivo (15). Inactivation of the MafK pathway may represent an effective genetic approach against oxidative stress-induced human diseases.

Several anti-inflammatory or anti-oxidative phytochemicals suppress NF-KB signaling and activate the Nrf2-ARE pathway (16-18) suggesting that the suppression of NF-KB signaling and the activation of the Nrf2-ARE pathway may crosstalk with each other. In previous studies, we found that Prunella vulgaris var. Iilacina possessed potent antioxidant and anti-inflammatory activities in vitro $(19,20)$. P. vulgaris var. lilacina contains various compounds which are flavonoids, triterpenoids, phenolic acids such as campherol, rutin, rosmarinic acid (RA), caffeic acid (CA), ursolic acid (UA), oleanolic acid (OA) and tannins that provide a great assortment of biological properties (21).

Thus, the purpose of this study was to determine the anti-inflammatory effects of major compounds of $P$. vulgaris var. lilacina including their inhibitory effects on inflammatory mediators and regulatory effects on NF- $\mathrm{KB}$ and Nrf2 signaling. In addition, we also examined whether major compounds of $P$. vulgaris var. lilacina modulates MafK expression to regulate NF- $\mathrm{KB}$ signaling.

ISSN: 1976-670X (electronic edition)

Copyright (C) 2014 by the The Korean Society for Biochemistry and Molecular Biology

cc) This is an open-access article distributed under the terms of the Creative Commons Attribution Non-Commercial License (http://creativecommons.org/licenses/by-nc/3.0) which permits unrestricted non-commercial use, distribution, and reproduction in any medium, provided the original work is properly cited. 


\section{RESULTS}

Cytotoxicity of $\boldsymbol{P}$. vulgaris var. lilacina compounds in RAW 264.7 cells

The cytotoxicities of several compounds were measured in RAW 264.7 cells by using MTT assay. Cells were treated with 4 compounds (RA, OA, UA, and CA) at various concentrations $(0,10$, 25, and $50 \mu \mathrm{M})$ for $1 \mathrm{~h}$ and then co-incubated with lipopolysaccharides (LPS; $1 \mu \mathrm{g} / \mathrm{mL}$ ) for an additional $24 \mathrm{~h}$. As shown in Fig. 1, in groups-treated with 25 and $50 \mu \mathrm{M}$ compounds, the viability range of RAW 264.7 cells after exposure was $43 \%$ to $91 \%$. In case of $10 \mu \mathrm{M}$ treated group, cell viability

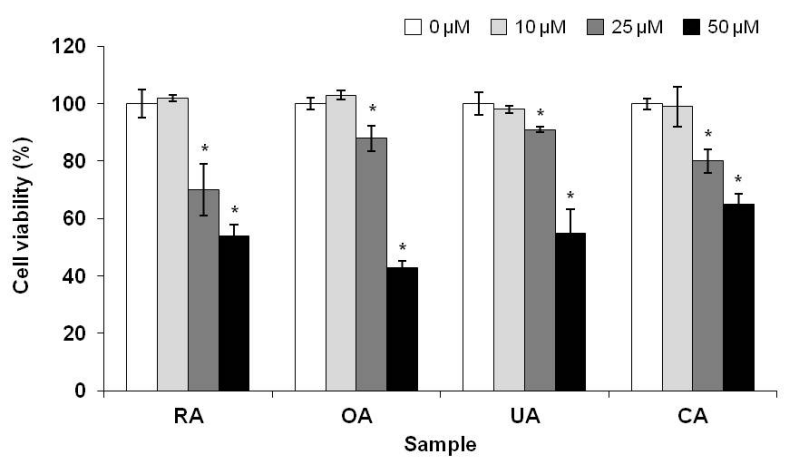

Fig. 1. Effects of major compounds from Prunella vulgaris var. lilacina on cell viability of RAW 264.7 cells. RAW 264.7 cells were treated with major compounds of $P$. vulgaris var. lilacina at different concentrations $(10,25$ and $50 \mu \mathrm{M})$. After treatment for $24 \mathrm{~h}$, Cell viability was quantified by MTT. The bars represent the means \pm SEM of 3 experiments performed in triplicate. Statistical significance was determined relative to a control by the Student's t-test ( $* \mathrm{P}<0.05$ compared with the $0 \mu \mathrm{M}$-treat group). RA, rosmarinic acid; OA, oleanolic acid; UA, ursolic acid; CA, caffeic acid. was not significantly affected by the compounds. Therefore, these compounds were used at $10 \mu \mathrm{M}$ in subsequent experiments.

\section{Inhibition of LPS-induced nitric oxide (NO) and prostaglandin E2 (PGE2) production in RAW 264.7 cells}

To determine whether the compounds inhibit LPS-induced NO production, RAW 264.7 cells were pretreated with each compound for $24 \mathrm{~h}$ and then stimulated with LPS $(1 \mu \mathrm{g} / \mathrm{ml})$. After 24 $\mathrm{h}$ of stimulation, the cell medium was harvested and the production of $\mathrm{NO}$ was measured using a Griess assay. As shown in Fig. 2A, we found that LPS treatment significantly increased $\mathrm{NO}$ production to $26.1 \mu \mathrm{M}$; however, RA, OA, UA, and CA reduced NO production by $46.2 \%, 30.0 \%, 37.3 \%$, and $27.3 \%$, respectively. We also evaluated the effects of the compounds on PGE2 production in LPS-stimulated RAW 264.7 cells. As shown in Fig. 2B, stimulation with LPS $(1 \mu \mathrm{g} / \mathrm{ml})$ for $24 \mathrm{~h}$ in the absence of the compounds caused RAW 264.7 macrophages to produce PGE2 at a concentration of $3.4 \mathrm{ng} / \mathrm{ml}$. However, RA, OA, UA, and CA significantly reduced the production of LPS-induced PGE2 by $21.8 \%, 42.8 \%, 28.4 \%, 38.1 \%$, respectively.

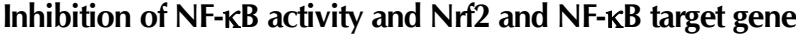 expression}

$\mathrm{NF}-\mathrm{KB}$ activation is necessary for pro-inflammatory responses $(22,23)$. Thus, we next examined the effects of the compounds on NF- $\mathrm{KB}$ activation by performing a luciferase activity assay. As shown in Fig. 3A, LPS treatment in the absence of the compounds induced NF-KB activity, while pretreatment with RA, $\mathrm{OA}, \mathrm{UA}$, and CA decreased NF-KB activity.

Because Nrf2 is known to suppress inflammation and NF- $\mathrm{KB}$ is known to induce inflammation (24-27), we examined the possibility that the compounds activate and inhibit Nrf2 and NF- $\mathrm{KB}$ signaling, respectively. First, we examined whether the compounds induced the expression of Nrf2 target genes such as
(A)

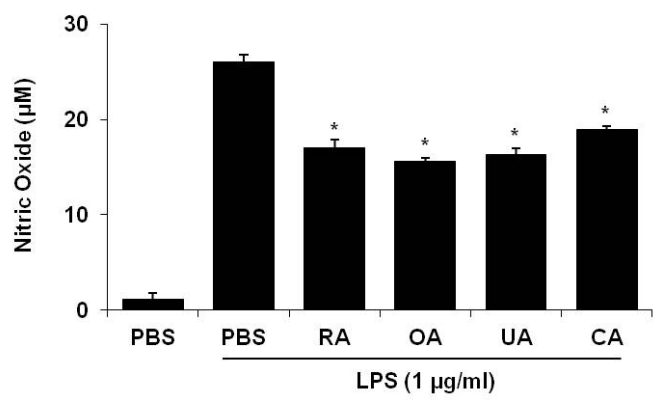

(B)

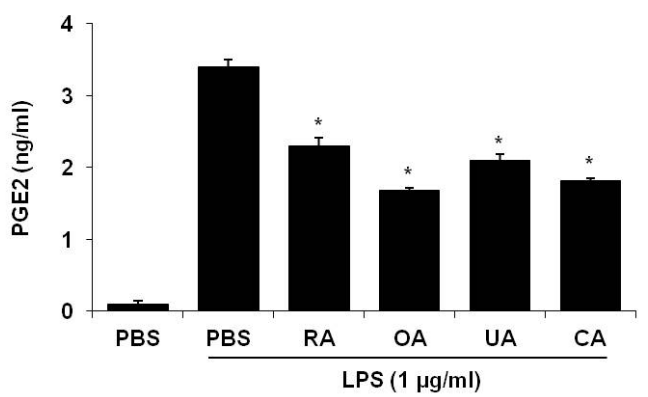

Fig. 2. Effects of major compounds from Prunella vulgaris var. lilacina on LPS-induced NO (A) and PGE2 (B) production in RAW 264.7 cells. RAW 264.7 cells were treated with main compounds $P$. vulgaris var. lilacina $(10 \mu \mathrm{M})$. After treatment, the supernatants were harvested and quantified the NO and PGE2 production using by ELISA. The bars represent the means \pm SEM of 3 experiments performed in triplicate. Statistical significance was determined relative to a control by the Student's $t$-test (*P $<0.05$ compared with the LPS group). RA, rosmarinic acid; OA, oleanolic acid; UA, ursolic acid; CA, caffeic acid. 
(A)

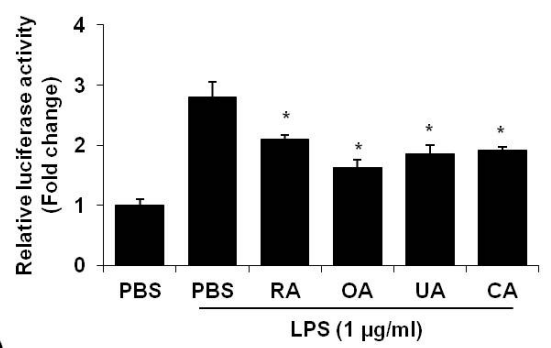

(B)

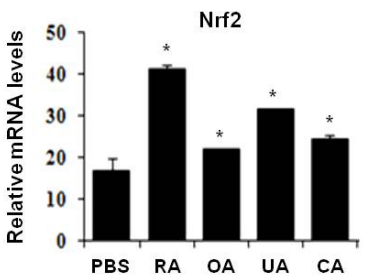

(C)

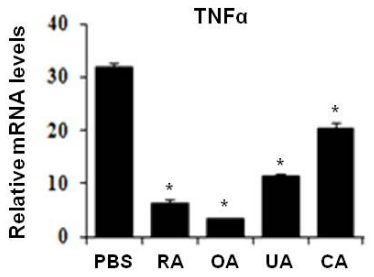

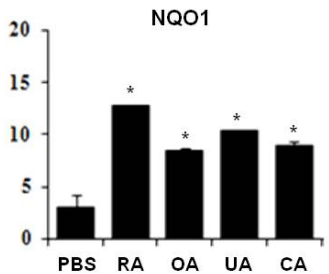

cIAP2

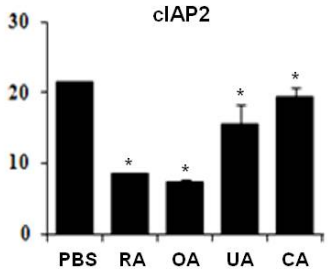

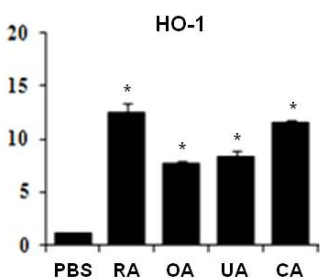

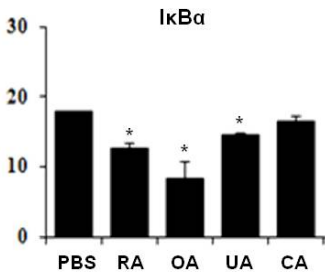

Fig. 3. Effect of major compounds from Prunella vulgaris var. lilacina on NF-KB activity (A) and Nrf2(B) and NF-KB (C)-dependent gene expression in LPS-induced RAW 264.7 cells. (A) The NF-kB-response-element-Luc reporter was transfected in RAW 264.7 cells. After $24 \mathrm{~h}$, cells were treated with LPS and $10 \mu \mathrm{M}$ of compounds. After $24 \mathrm{~h}$, cells were lysed for the luciferase assay. (B and C) RAW 264.7 cells were treated with compounds 10 $\mu \mathrm{M}$. After treatment for $24 \mathrm{~h}, \mathrm{RNA}$ was isolated and reverse-transcribed for RT-PCR analyses. The bars represent the means + SEM of 3 experiments performed in triplicate. Statistical significance was determined relative to a control by the Student's $t$-test $(* \mathrm{P}<0.05$ compared with the control group). RA, rosmarinic acid; OA, oleanolic acid; UA, ursolic acid; CA, caffeic acid.
NQO1 and HO-1. The RAW 264.7 cells were treated with each of the 4 compounds. Total RNA was extracted from the treated cells and Nrf2, NQO1, and HO-1 mRNA expression was analyzed using real-time reverse-transcription polymerase chain reaction (RT-PCR). As shown in Fig. 3B, expression of these 3 genes was induced by each of the 4 compounds. Next, we determined the effect of the compounds on NF- $\mathrm{kB}$ target gene expression. As shown in Fig. 3C, each of the 4 compounds inhibited the expression of NF- $\mathrm{\kappa B}$ target genes, including those encoding TNF $\alpha$, clAP2, and $\mathrm{I} \mathrm{KB} \alpha$. Taken together, these results show that the 4 compounds are associated with Nrf2 activation and NF-kB suppression.

\section{The effect of the compounds on MafK-mediated NF-KB signaling}

In a previous study, we showed that MafK is a novel modulator of NF-KB. Inactivation of the MafK expression would be regulating the NF-KB signaling (15). Here, we investigated whether the compounds from $P$. vulgaris var. lilacina could modulate MafK expression. As shown in Fig. 4A, OA significantly decreased MafK expression, while the other compounds had no effect. Therefore, among major compounds of $P$. vulgaris var, lilacina, OA could be expecting to regulate the expression of MafK as a NF-KB inhibitor.

To determine whether the OA-mediated inhibition of MafK

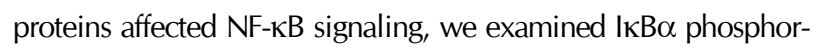

ylation and its subsequent degradation. As shown in Fig. 4B, OA-treated group and knockdown of MafK group did not significantly inhibit TNF $\alpha$-induced $1 \kappa B \alpha$ degradation or phosphorylation. However, we found that OA-treated group in MafK knockdown cell inhibited IKB $\alpha$ phosphorylation, which was synergistically inhibited by the OA. And as previously reported, we confirmed that MafK knockdown cell were decreased the p65 acetylation. Because OA reduced the MafK expression, OA-treated group would be reducing the p65 acetylation by reduced MafK. In addition, when simultaneously OA and siMafK treat to cell, p65 acetylation did not observe. Taken together, we suggest that $\mathrm{OA}$ regulates $\mathrm{NF}-\mathrm{KB}$ signaling via regulation of MafK expression.

\section{DISCUSSION}

In our previous study, we demonstrated that $P$. vulgaris var. lilacina has significant anti-inflammatory effects through inhibiting the release of inflammatory mediators and cytokines, which might be due to its blocking of the NF-KB signaling pathway (20). And also, we identified that a novel function of MafK, which can act as a modulator of NF-KB (15). As a following study, we focused on anti-inflammatory and MafK regulating effect of major compounds of $P$. vulgaris var. lilacina.

The Nrf2- NF- $\mathrm{KB}$ pathway is a viable therapeutic target for protection against oxidative stress in various diseases. Several Nrf2 
(A)

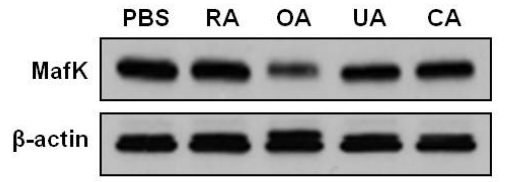

(B)

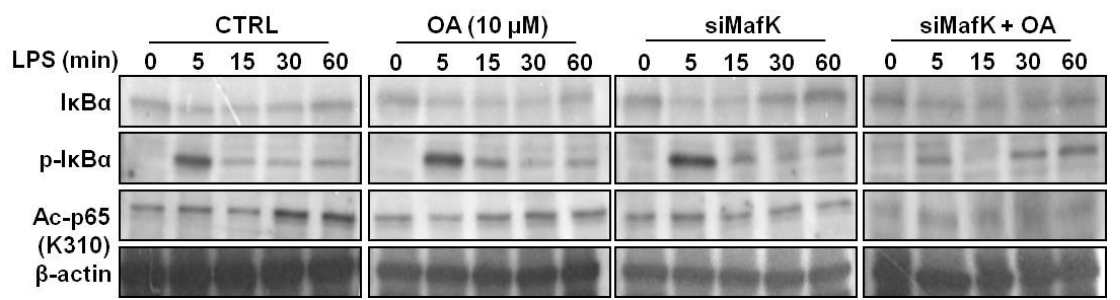

Fig. 4. Effects of major compounds from Prunella vulgaris var. lilacina on MafK expression and NFKB signaling in MafK depletion cells. (A) RAW 264.7 cells were treated with compounds $(10 \mu \mathrm{M})$. After treatment for $24 \mathrm{~h}$, whole cell lysates were subjected to western blot analysis of anti-MafK. $\beta$-actin was used as internal control. (B) RAW 264.7 cells were transfected with siMafK or control siRNA and after $24 \mathrm{~h}$, cells were treated with OA $(10 \mu \mathrm{M})$. And after another 24h, LPS (1 $\mu \mathrm{g} / \mathrm{mL})$ followed by measurement of $I \kappa B \alpha$ degradation, phosphorylation and p65 acetylation in lysates after 5, 15, 30, and $60 \mathrm{~min}$. $\beta$-actin was used as internal control. $\mathrm{RA}$, rosmarinic acid; OA, oleanolic acid; UA, ursolic acid; CA, caffeic acid. activating and NF-KB inhibiting small molecules have been identified (28-33). Curcumin, a polyphenolic compound that acts via $\mathrm{Nrf} 2$, is suggesting that curcumin-activated Nrf2 modulates the expression and transactivation of NF- $\mathrm{KB}$ p65 protein levels, DNA-binding activity and promoter activity of NF- $\mathrm{KB}$, increase in Nrf2 overespressing cells in the presence of curcumin (28). Phenethyl isothiocyanate (PEITC) and sulforaphane attenuated LPS induced NF- $\kappa B$ activation via inhibit IKK/IKB phosphorylation and p65 NF- $\mathrm{kB}$ subunit nuclear translocation, consequently alleviating NF- $\kappa B$ signaling (29) and It activates Nrf2, possibly by modifying the sensor cysteines present in Keap1 (30, 31). The EGCG inhibited activation of NF-KB and AP-1 thereby suppressing the COX-2 induction in mouse skin in vivo and/or cultured human mammary epithelial (MCF10A) cells (32). EGCG also upregulated antioxidant enzymes by activating the Nrf2ARE signaling pathway (33). In the present study, we evaluated the regulatory effects of major compounds such as RA, OA, UA and CA of $P$. vulgaris var. lilacina on these signaling pathways and the expression of pro-inflammatory mediator, such as NO and PGE2 in LPS-stimulated RAW 264.7 macrophages. The data obtained from our current study indicated that RA, OA, UA and CA significantly inhibited LPS-induced NO and PGE2 production in RAW 264.7 cells. In addition, we found that RA, OA, UA and CA exert their inhibitory effects on these inflammatory responses via the suppression of NF-KB in the LPS-stimulated RAW 264.7 cells. Taken together, these data suggest that RA, OA, UA and CA from $P$. vulgaris var. lilacina contributes to anti-inflammatory effects by suppressing NF-kB activity.

The multitude of possible interactions in the Nrf2- NF- $\mathrm{BB}$ pathway makes the design of novel Nrf2- NF-kB pathway regulators especially difficult. Nevertheless, we identified MafK as the new regulator of Nrf2- NF-кB pathway. To find new chemicals for regulation of Nrf2- NF- $\mathrm{KB}$ pathway via inhibiting the MafK expression, based on the results of the present study, we evaluated the inhibition of MafK expression by RA, OA, UA and CA compounds. In the results, we confirmed a single compound "OA" with greatly inhibition than other compounds. OA significantly suppressed MafK expression and subsequently activate I $\mathrm{B} \alpha$ phosphorylation, inhibit the p65 acetylation. Taken together, these results suggest that the suppression of MafK expression by $\mathrm{OA}$ is mediated by the inhibition of NF-KB activation.

In conclusion, our results suggest that $\mathrm{OA}$, a major compound of $P$. vulgaris var. lilacina, exerts potent anti-inflammatory effects by inhibiting LPS-induced NO, PGE2 in RAW 264.7 cells. These effects are mediated by inhibition of NF-KB activity via suppression of MafK expression. These findings suggest that $\mathrm{OA}$ as $\mathrm{NF}-\kappa \mathrm{B}$ inhibitors can potentially be used in therapeutic applications for the treatment of oxidative stress-induced diseases.

\section{MATERIALS AND METHODS}

\section{Reagents}

Rosmarinic acid, oleanolic acid, ursolic acid, caffeic acid and LPS from Escherichia coli O55:B5 were purchased from SigmaAldrich (St. Louis, MO, USA). Dulbecco's Modified Eagle's Medium (DMEM), fetal bovine serum (FBS), and penicillin- streptomycin were obtained from Invitrogen (Carlsbad, CA, USA). Antibodies against $I \kappa B \alpha, p$-I $\mid \kappa \beta \alpha$, and $\beta$-actin were purchased from Cell Signaling Technology (Danvers, MA, USA). Monoclonal antibodies against MafK and Acetyl-p65 (K310) were purchased from Abcam (Cambridge, MA, USA). The NF-KB-luciferase vector was purchased from Promega (Madison, WI, USA). All other chemicals were purchased from Sigma unless otherwise specified.

\section{Cell culture and viability}

The RAW 264.7 macrophage cell line was purchased from the Korean Cell Line Bank (Seoul, Korea). RAW 264.7 cells were cultured in DMEM containing $10 \%$ FBS and $1 \%$ penicillin/streptomycin at $37^{\circ} \mathrm{C}$ in $5 \% \mathrm{CO}_{2}$. To investigate the cell vi- 
ability of compounds cells $\left(1 \times 10^{4}\right.$ cells/well $)$ were added to duplicate 96-well plates and incubated for $24 \mathrm{~h}$, then treated with various concentrations (10, 25, and $50 \mu \mathrm{M})$ of compounds for $24 \mathrm{~h}$. Cell viability was measured using MTT assay.

\section{NO Measurement}

Nitrite was measured as an indicator of NO production after 48 $\mathrm{h}$ of treatment and LPS induction. The culture supernatant (100 $\mu \mathrm{l}$ ) was placed in a 96-well plate, and an equal amount of Griess reagent ( $2 \%$ sulphanilamide and $0.2 \% \quad \mathrm{~N}$-1-(naphthyl) ethylenediamine dihydrochloride in $5 \% \mathrm{H}_{3} \mathrm{PO}_{4}$ ) was added. The plate was then incubated for $10 \mathrm{~min}$ and the absorbance measured at $540 \mathrm{~nm}$. The amount of NO was calculated using a sodium nitrite standard curve.

\section{PGE2 Measurement}

After $12 \mathrm{~h}$ of treatment and LPS stimulation, the culture supernatant was collected. PGE2 was measured using a PGE2 ELISA kit following the manufacturer's instructions (Abcam). Briefly, the diluted cell supernatant $(100 \mu \mathrm{l})$ was placed in a 96-well goat anti-mouse IgG-coated plate and incubated for $2 \mathrm{~h}$. After incubation, the plate was washed using the provided washing buffer, and the color was developed by adding PNPP (200 $\mu \mathrm{l})$ substrate after $45 \mathrm{~min}$. The amount of PGE2 was calculated by using a PGE2 standard curve.

\section{Transfection of RAW 264.7 cells with pNF-kB luciferase vector}

RAW 264.7 cells were transiently transfected with a pNF-KB-luciferase vector by using Lipofectamine 2000 (Invitrogen) following the manufacturer's protocol. Briefly, $5 \times 10^{4}$ cells were placed in a 24-well plate and allowed to grow to $80-90 \%$ confluence for $24 \mathrm{~h}$. The cells were then treated with DNA-Transfast reagent mixture $(50 \mu \mathrm{l})$ and incubated for $16 \mathrm{~h}$. The amount of DNA added was $0.25 \mu \mathrm{g} /$ well. After $16 \mathrm{~h}$ of incubation, each well was overlaid with $1 \mathrm{ml}$ of complete growth medium and the transfection was carried out for $48 \mathrm{~h}$.

\section{Real-time RT-PCR analysis}

To determine the expression levels of Nrf2, NQO-1, HO-1, TNF $\alpha$, clAP2 and, IKB $\alpha$ mRNAs, real-time RT-PCR was performed using a Qiagen Rotorgene Q thermal cycler (Valencia, CA, USA) according to the manufacturer's instructions. The cells were treated with RA, OA, UA and CA and cultured for $12 \mathrm{~h}$. Thereafter, cDNA was synthesized from the total RNA isolated from cells. The real-time PCR reactions were performed using 2 $\times$ SYBR Green mix (Qiagen). All results were normalized to glyceraldehyde 3-phosphate dehydrogenase (GAPDH) expression. Primer sequences are as follows: GAPDH, 5'-GAGCCAAAAG GGTCATCATC-3' (forward), 5'-TAAGCAGTTGGTGGTGCAGG-3' (reverse); TNF $\alpha$, 5'-AGCACAGAAAGCATGATCCG-3' (forward), 5'-GTTTGCTACGACGTGGGCTA-3' (reverse); CIAP2, 5'-ATTTGA TGAAAAGCGCCAAC-3' (forward), 5'-AAACCAGCACGAGCAAG ACT-3' (reverse); IKB $\alpha$, 5'-GCTGAAGAAGGAGCGGCTACT-3' (forward), 5'-TCGTACTCCTCGTCTTTCATGGA-3' (reverse); Nrf2, 5'-GAGACAGGTGAATTTCTCCCAAT-3'(forward), 5'-TTTGGGA ATGTGGGCAAC-3' (reverse); NQO1, 5'-CAGCTCACCGAGAGC CTAGT-3' (forward), 5'-GAGTGAGCCAGTACGATCAGTG-3' (reverse); HO-1 5'-GGGTGATAGAAGAGGCCAAGA-3' (forward), 5'-AGСТССТGCAАСТССТСAAA-3' (reverse).

\section{Immunoblotting}

Cells were lysed in radioimmunoprecipitation assay buffer (150 $\mathrm{mM} \mathrm{NaCl}, 1 \%$ Triton $\mathrm{X}-100,1 \%$ sodium deoxycholate, $0.1 \%$ SDS, $50 \mathrm{mM}$ Tris-HCl, $\mathrm{pH} 7.5$, and $2 \mathrm{mM}$ EDTA) on ice for 30 $\min$. After centrifugation at $4^{\circ} \mathrm{C}$ for $20 \min (12,000 \times$ g), the supernatant was collected. Protein concentrations were determined using a BCA assay (GenDEPOT; Barker, TX, USA). Equal amounts of cell extracts were separated using $12.5 \%$ SDS-PAGE and transferred to polyvinylidene difluoride membranes (Bio- Rad; Hercules, CA, USA). The membranes were blotted with antibody and detection was performed using an ECL system (Pierce; Rockford, IL USA) according to the manufacturer's instructions.

\section{Transfection of small interfering RNA (siRNA)}

Human siRNA oligonucleotides were purchased from Integrated DNA Technologies. RAW 264.7 cells were transfected with siRNA oligos by using Lipofectamine RNAi max (Invitrogen). Twenty- four hours post-transfection, cells were treated with LPS $(1 \mu \mathrm{g} / \mathrm{ml})$, and were then harvested. The siRNA sense oligo sequences were as follows: control, 5'-UUCUCCGAACGUGUCA CGUTT-3'; siMafK, 5'-GCCATACGCGUUUGTTCAUTT-3'.

\section{Statistical analysis}

Statistical analyses were performed with SPSS statistical software (version 12.0). The data represent means \pm standard errors of the mean from 3 independent experiments unless otherwise stated. Statistical analyses were performed by the Student's $t$-test at a significance level of $P<0.05$.

\section{ACKNOWLEDGEMENTS}

This study was carried out with the support of the Research Program for Agricultural Science \& Technology Development (Project No. PJ00846201), National Academy of Agricultural Science, Rural Development Administration, Korea.

\section{REFERENCES}

1. Yuan, Q., Zhang, X., Liu, Z., Song, S., Xue, P., Wang, J. and Ruan, J. (2013) Ethanol extract of Adiantum capillus-veneris L. suppresses the production of inflammatory mediators by inhibiting NF-KB activation. J. Ethnopharmacol. 147, 603-611.

2. De Heredia, F. P., Gomez-Martinez, S. and Marcos, A. (2012) Obesity, inflammation and the immune system. Proc. Nutr. Soc. 71, 332-338.

3. Guha, M. and Mackman, N. (2001) LPS induction of gene expression in human monocytes. Cell Signal. 13, 85-94. 
4. Yamamoto, Y. and Gaynor, R. B. (2001) Role of the NF-kappaB pathway in the pathogenesis of human disease states. Curr. Mol. Med. 1, 287-296.

5. Bharti, A. C. and Aggarwal, B. B. (2002) Nuclear factor-kappa $B$ and cancer: its role in prevention and therapy. Biochem. Pharmacol. 64, 883-888.

6. Garg, A. and Aggarwal, B. B. (2002) Nuclear transcription factor-kappaB as a target for cancer drug development. Leukemia 16, 1053-1068.

7. Gilroy, D. W., Lawrence, T., Perretti, M. and Rossi, A. G. (2004) Inflammatory resolution: new opportunities for drug discovery. Nat. Rev. Drug Discov. 3, 401-416.

8. Moi, P., Chan, K., Asunis, I., Cao, A. and Kan, Y. W. (1994) Isolation of NF-E2-related factor 2 (Nrf2), a NF-E2-like basic leucine zipper transcriptional activator that binds to the tandem NF-E2/AP1 repeat of the b-globin locus control region. Proc. Natl. Acad. Sci. U.S.A. 91, 9926-9930.

9. Motohashi, H. and Yamamoto, M. (2004) Nrf2-Keap1 defines a physiologically important stress response mechanism. Trends Mol. Med. 10, 549-557.

10. Jeong, W. S., Jun, M. and Kong, A. N. (2006) Nrf2: A Potential Molecular Target for Cancer Chemoprevention by Natural Compounds. Antioxid. Redox Signal. 8, 99-106.

11. Kwak, M. K. and Kensler, T. W. (2010) Targeting NRF2 signaling for cancer chemoprevention. Toxicol. Appl. Pharmacol. 244, 66-76.

12. Li, W., Khor, T. O., Xu, C., Shen, G., Jeong, W. S., Yu, S. and Kong, A. N. (2008) Activation of Nrf2-antioxidant signaling attenuates NFKB-inflammatory response and elicits apoptosis. Biochem. Pharmacol. 76, 1485-1489.

13. Liu, G. H., Qu, J. and Shen, X. (2008) NF-kB/p65 antagonizes Nrf2-ARE pathway by depriving CBP from Nrf2 and facilitating recruitment of HDAC3 to MafK. Biochim. Biophys. Acta. 1783, 713-727.

14. Yu, M., Li, H., Liu, Q., Liu, F., Tang, L., Li, C., Yuan, Y., Zhan, Y., Xu, W., Li, W., Chen, H., Ge, C., Wang, J. and Yang, X. (2011) Nuclear factor p65 interacts with Keap1 to repress the Nrf2-ARE pathway. Cell Signal. 23, 883-892.

15. Hwang, Y. J., Lee, E. W., Song, J., Kim, H. R., Jun, Y. C. and Hwang, K. A. (2013) MafK positively regulates NF-kB activity by enhancing CBP-mediated p65 acetylation. Sci. Rep. 3, 3242 .

16. Kwon, D. J., Bae, Y. S., Ju, S. M., Youn, G.S., Choi, S. Y. and Park, J. (2014) Salicortin suppresses lipopolysaccharide-stimulated inflammatory responses via blockade of NF-KB and JNK activation in RAW 264.7 macrophages. BMB Rep. 47, 318-323.

17. Jeong, J. B., Hong, S. C., Jeong, H. J. and Koo, J. S. (2011) Anti-inflammatory Effect of 2-Methoxy-4-Vinylphenol via the Suppression of NF-KB and MAPK Activation, and Acetylation of Histone H3. Arch. Pharm. Res. 34, 2109-2116.

18. Jeong, J. H., Ryu, D. S., Suk, D. H. and Lee, D. S. (2011) Anti-inflammatory effects of ethanol extract from Orostachys japonicus on modulation of signal pathways in LPS-stimulated RAW 264.7 cells. BMB Rep. 44, 399-404.

19. Hwang, Y. J., Lee, E. J., Kim, H. R. and Hwang, K. A. (2013) In vitro antioxidant and anticancer effects of solvent fractions from prunella vulgaris var. lilacina. BMC Complement. Altern. Med. 13, 310

20. Hwang, Y. J., Lee, E. J., Kim, H. R. and Hwang, K. A. (2013)
NF-кB-Targeted Anti-Inflammatory Activity of Prunella vulgaris var. lilacina in Macrophages RAW 264.7. Int. J. Mol. Sci. 14, 21489-21503.

21. Lamaison, J. L., Petitjean-Freytet, C. and Carnat, A. (1991) Medicinal Lamiaceae with antioxidant properties, a potential source of rosmarinic acid. Pharm. Acta. Helv. 66, 185-188.

22. Lockyer, J. M., Colladay, J. S., Alperin-Lea, W. L., Hammond, T. and Buda, A. J. (1998) Inhibition of nuclear factor-kappaB-mediated adhesion molecule expression in human endothelial cells. Circ. Res. 82, 314-320.

23. Marui, N., Offermann, M. K., Swerlick, R., Kunsch, C., Rosen, C. A., Ahmad, M., Alexander, R. W. and Medford, R. M. (1993) Vascular cell adhesion molecule-1 (VCAM-1) gene transcription and expression are regulated through an antioxidant-sensitive mechanism in human vascular endothelial cells. J. Clin. Invest. 92, 1866-1874.

24. Chen, X. L. and Kunsch, C. (2004) Induction of Cytoprotective Genes through Nrf2/Antioxidant Response Element Pathway: A New Therapeutic Approach for the Treatment of Inflammatory Diseases. Curr. Pharm. Des. 10, 879-891.

25. Thimmulappa, R. K., Lee, H., Rangasamy, T., Reddy, S. P., Yamamoto, M., Kensler, T. W. and Biswal, S. (2006) Nrf2 is a critical regulator of the innate immune response and survival during experimental sepsis. J. Clin. Invest. 116, 984-995.

26. Tak, P. P. and Firestein, G. S. (2001) NF-kB: a key role in inflammatory diseases. J. Clin. Invest. 107, 7-11.

27. Pikarsky, E., Porat, R. M., Stein, I., Abramovitch, R., Amit, S., Kasem, S., Gutkovich-Pyest, E., Urieli-Shoval, S., Galun, E. and Ben-Neriah, Y. (2004) NF-KB functions as a tumour promoter in inflammation-associated cancer. Nature 431, 461-466.

28. Balogun, E., Hoque, M., Gong, P., Killeen, E., Green, C. J., Foresti, R., Alam, J. and Motterlini, R. (2003) Curcumin activates the haem oxygenase-1 gene via regulation of Nrf2 and the antioxidant-responsive element. Biochem. J. 371, 887-895.

29. Heiss, E., Herhaus, C., Klimo, K., Bartsch, H. and Gerhauser, C. (2001) Nuclear factor kappa B is a molecular target for sulforaphanemediated anti-inflammatory mechanisms. J. Biol. Chem. 276, 32008-32115.

30. Thimmulappa, R. K., Mai, K. H., Srisuma, S., Kensler, T. W., Yamamoto, M. and Biswal, S. (2002) Identification of Nrf2-regulated genes induced by the chemopreventive agent sulforaphane by oligonucleotide microarray. Cancer Res. 62, 5196-5203.

31. Gao, X. and Talalay, P. (2004) Induction of phase 2 genes by sulforaphane protects retinal pigment epithelial cells against photooxidative damage. Proc. Natl. Acad. Sci. U.S.A. 101, 10446-10451.

32. Kundu, J. K., Na, H. K., Chun, K. S., Kim, Y. K., Lee, S. J., Lee, S. S., Lee, O. S., Sim, Y. C. and Surh, Y. J. (2003) Inhibition of Phorbol Ester-Induced COX-2 Expression by Epigallocatechin Gallate in Mouse Skin and Cultured Human Mammary Epithelial Cells. J. Nutr. 133, 3805S-3810S.

33. Na, H. K. and Surh, Y. J. (2008) Modulation of Nrf2- mediated antioxidant and detoxifying enzyme induction by the green tea polyphenol EGCG. Food Chem. Toxicol. 46, 1271-1278. 